\title{
LO GROTESCO EM GALDOS RECURSOS PARA LA SATIRA POLITICA DE LOS ULTIMOS EPISODIOS
}

\author{
Luis Lorenzo-Rivero*
}

\section{PREÁMBULO}

La obra de Benito Pérez Galdós fue el vehículo de sus intenciones trascendentales, las cuales sólo se pueden entender dentro de la corriente del tiempo. El peculiarísimo mundo de su ficción refleja los elementos mås significativos de la realidad inmediata. En Madrid captó el panorama vigoroso de la calle, alcanzando sus vivencias de aquellos turbulentos momentos expresión adecuada años después. Peter Bly mantiene que a Galdós le importaban, por encima de todo, las causas de los acontecimientos políticos. ${ }^{1}$ Sus fundamentos filosóficos, sin embargo, eran para Hans Hinterhäuser de un caråcter muy general. ${ }^{2}$ La tarea primordial de los últimos Episodios, y también de Fortunata y Jacinta, que son las obras consideradas aquí, fue la de despertar en el enfermo pueblo espanol la pasión del patriotismo. Los Episodios pretendían además servir de viva lección para el futuro, ${ }^{3}$ arirmación corroborada por las propias palabras del novelista en La Primera República: "Al retirarme, vi en mi mente con absoluta claridad que mi papel en el mundo no era determinar los acontecimientos, sino observarlos y con vulgar manera describirlos para que de ellos pudieran sacar alguna enseñanza los venideros hombres. De tales ensenanzas podía resultar que acelerasen el paso las generaciones destinadas a llevarnos a la plenitud de los tiempos." $" 4$

Las "camarillas", que establecieron como norma de conducta el "caciquismo" contra el que luchaba en vano la hambrienta e inculta mayoría, constituían el el pensamiento galdosiano el mayor mal de Espana. Consideraba que la solución consistra en la eliminación del profundo abismo que distanciaba a los intelectuales del vulgo, juguete de los intrigantes gobernantes, y también del clero. En Amadeo I se encuentra su disgusto con la meso- 
cracia de los políticos espafioles, expresado en estos términos: "Eran siempre los de siempre, ni mejores ni más malos que los anteriores y subsiguientes. ¿Qué hacían? Ir viviendo, ir trazando una historia tediosa y sin relieve, sobre cuyas páginas, escritas con menos tinta que saliva, pasaban pronto las aguas del olvido" (IV, 487). De ahora en adelante, aunque siempre dentro del ideario burgués y liberal, se fue abriendo cada vez más al amor por los desposeídos y por los que sufrian. ${ }^{5}$

Entre la multiplicidad de recursos que utilizó Galdós con el fin de dramatizar mejor la causa de la libertad y progreso del pueblo frente a los abusos de los políticos, de la monarquía absoluta y del fanatismo clerical, uno de los más efectivos fue el elemento grotesco. Aunque varios críticos han hecho referencias a este aspecto del arte galdosiano, sólo dos lo han tratado directamente: primero, B.J. Zeidner Bäuml en su importante artículo sobre Torquemada en la hoguera y más recientemente John Kronik en un excelente artículo de carácter más general. ${ }^{6} \mathrm{El}$ aspecto satírico de la obra de Galdós exigía el uso de lo grostesco, afirmación hecha ya por Mariano Baquero Goyanes: “... el encuadramiento del arte descriptivo quevedesco, como arte realista a la manera hispánica, se convierte en justificación y poco menos que en razón del ser del arte descriptivo galdosiano, hecho de realismo y desmesura, de concreción e hipérbole, de exactitud y de fábula." " En el comienzo Galdós se sirvió de recursos grotescos y caricaturescos para su crítica de la lamentable situación nacional, técnica que también utilizó en Amadeo I, La Primera República, Cánovas, etc., de manera similar a Quevedo, Goya y Larra: “... to reveal specific aspects of social reality, to make that which is disfigured, immoral, or criminal susceptible to immediate sensory cognition." 8 Lo grotesco en sus novelas tiene simultáneamente una función estética e ideológica. Ahora bien, puesto que el término grotesco se ha prestado a numerosas y variadas interpretaciones, conviene clarificar el sentido que se le da aquí. Se entiende de una manera más de acuerdo con los tiempos modernos, algo semejante a Kronik, quien lo considera: “... a plastic conception of the literary art; a juxtaposition of components that are perceived as incompatible, especially a fusion of reality and its contradiction; a sense of alienation-that is, a feeling of discomfort, of estrangement from an order; a distortion of lines that is more extreme and more problematic than the caracaturesque; and finally, a stimulus to laughter in which we sense a measure of unhealthiness." A esto afiade que el antiguo elemento de lo demoníaco está atenuado en el concepto moderno de grotesco, pero se conservan todavía la distorsión, el exceso, las discrepancias, el juego de máscaras y los elementos cómicos. 


\section{POLITIICOS MENGUADOS Y GROTESCO FANTÁSTICO}

Puesto que lo grotesco sólo se manifiesta en um ambiente propicio, pocas circunstancias más favorables se pueden encontrar que las narradas en la última serie de los Episodios nacionales y en Fortunata y Jacinta. En estas obras Galdós se ocupó de una sociedad en caos, que buscababa arreglo a su tremendo desbarajuste. En lo que iba de siglo, el país había demostrado poca habilidad para hacer reformas que mejorasen las condiciones de los necesitados. La situación se tornó más difícil a partir de la aparición en 1844 de "La Joven Espafia" acaudillada por Luiz González Bravo, la cual se convirtió en una especie de pandilla que, actuando en un ambiente favorable a todo tipo de inmoralidades políticas, ofrecía sus servicios al mejor postor. ${ }^{10}$ Desde entonces se acentuó la manipulación electoral cada vez com mayor descaro hasta convertirse en la base del procedimiento político de Antonio Cánovas del Castillo. También se debe incluir entre los culpables de tan deplorable situación la propia Isabel II, quien incapaz de reconocer la realidad del país, se preguntaba sorprendida: "¿Por qué los espanoles no han de amarse los unos a los otros?"11 Desafortunadamente su expulsión, a pesar de prometer Prim a las Cortes Constituyentes en febrero de 1869 que los Borbones jamás volverían a gobernar en Espana, no solucionó los graves problemas. En consecuencia, según Miguel Enguídanos: "En el saldo final de su obra que es esta serie, Galdós no salva ni al estado, ni a la dinastía, ni a las personas que la componen, ni a la aristocracia, ni a la burguesía, ni a los políticos... ni a los profesionales, ni a los militares ni a los sacredotes." ${ }^{12}$ Históricamente todos tuvieron la culpa del drama espanol.

En 1868, a los tres días de haber formado gobierno, Juan Prim pidió la disolución de la Junta Superior Revolucionaria para consolidar la nueva situación, trayendo para rey al hijo de Víctor Manuel de Italia. Amadeo llegó a Espafia momentos después del asesinato de su protector, acto que significaba el fracaso de la que prometía ser la monarquía de la esperanza antes ya de jurar la Constitución. Incluso atentaron contra su propia vida para deshacerse de él cuanto antes. Galdós condenó con severidad y amargura por meio de Pepe Ferreras tan mezquinas fechorías:

No se concibe mayor oprobio de un país, ni mayor torpeza de las clases altas, que nos han traf́do la intervención del fango social en la vida política. En el estúpido atentato contra el Rey y en esta farándula repugnante veo yo el principio del fin. La responsabilidad es de todos, sin excluir las 
instituciones. Queríamos un Gobierno constitucional, sensato, estable, y en dos anos llevamos ya seis crisis, si no recuerdo mal. En política todo puede admitirse, menos el barullo, el caos y la falta de orientación. (IV, 568)

Esto implica asimismo una defensa de su ideología progresista, que era lo que la monarquía de Saboya representaba para él. En su visión, los políticos españoles recurrían a la bellaquerf́a bajo la pretensión de sincero patriotismo.

Apenas desterrada Isabel II, el Comité Republicano declaró que la República era el fundamento de la democracia e instigó levantamientos armados, reprimidos por Prim con dureza. Sin embargo no implantó un régimen personal, ya que el orden le servía sólo de medio para establecer una monarquía constitucional. El seis de junio se promulgó la Constitución más liberal, sistemática y racional que jamás había tenido la nación. Pero los republicanos continuaron su camino durante el corto reinado de Amadeo I hasta proclamar la República. A ese progresivo e inmediato hundimiento del monarca contribuyeron también las demás facciones. Una de las causas principales de la caída del monarca saboyano fue la doble imposibilidad de resolver a la muerte de Prim el problema de la jefatura y la cohesión del partido progresista. Práxedes Mateo Sagasta, apoyado por los unionistas, rompió de una manera definitiva con los progresistas, formando por su cuenta el partido progresista constitucional al que dió una marcada dirección de conservadurismo. ${ }^{13}$ Galdós, que indudablemente debió considerarlo el mayor culpable de la renuncia de don Amadeo, y consecuentemente de toda la catástrofe espanola posterior, ridiculizó por ello su persona y sus acciones políticas en un retrato a la manera de Quevedo y Larra, que también recuerda mucho algunas caricaturas grotescas de Goya: "Sagasta era otra vez el gallo de nuestro corral político, y con su arrogante cresta o tupé, su quiquiriqui tribunicio y el irisado plumaje de su simpatía personal, dominaría las olas que socababan el trono de Amadeo I" (IV, 514). Partiendo de un pequeño detalle físico del siniestro político, el mechón arremolinado que tenía sobre la frente, el escritor elaboró ese duro ataque contra su ambicioso e irresponsable comportamiento político.

La Espana de 1873 se le figuraba a Galdós una selva de densa vegetación, en la cual resultaba enormemente difícil habrirse camino y sacar algo aprovechable de entre tanta maleza. De ahí que su visión de los republicanos en La Primera República fuera la de seres infrahumanos con repelentes manipulaciones políticas: 
En lo alto, bandadas de cotorras y otras aves parleras aturden con su charla retórica; abajo, alimafias saltonas o reptantes, antropoides que suben y bajan por las ramas hostigándose unos a otros, sin que ninguno logre someter a los demås; millonadas de espléndidas mariposas, millonadas de zânganos zumbantes y molestos; rayos de sol que iluminan la fronda espesa; negros vapores que la sumergen en temerosa penumbra. (IV, 581)

Aquí, como en muchos otros casos, utilizó la técnica satírica del grotesco en su interpretación de la decadencia político-social y en su proyección del enajenamiento psíquico. ${ }^{14}$ Hay que tener presente además la vileza de los monárquicos, quienes contribuyeron a derribar la monarquía que atestiguaban defender. Se abalanzaron sobre sus despojos en el momento que Pi y Margall proclamó la República, a cuya acción casi sólo se opuso Ruiz Zorrilla. También se deben anadir los asaltos del 23 de abril a la República, ejecutados por los radicales a instigaciones de Nicolás María Rivero con la participación de numerosos generales, como Pavía, Acosta, Serrano y otros. Anteriormente, al condenar los actos republicanos de la noche del 10 al 11 de febrero de 1873 con motivo de la renuncia de don Amadeo, Galdós vio en Rivero un monstruo homérico: 'Por la voz, el ceno y el ademán, don Nicolás María Rivero era un cíclope ceceoso que hablaba dando martillazos sobre un yunque" (IV, 575). Así censuró la frenética oposición de este despreciable ser al intento de Ruiz Zorrilla de disuadir al rey a que demitiera. Este retrato incluye también la reprobación de la política republicana entera y su forma de operar. Con la descripción hiperbólico-grotesca del individuo, el novelista solía satirizar todo el partido o grupo. Tal se ve en el caso del ficticio Hinojosa, el tío de Odulia la segunda amante de Tito, el cual representaba aquel sinnúmero de parásitos políticos que solían adherirse al partido en el poder, pero sin ningún tipo de ideología. Su propósito era vivir sangrando al país: "- Conozco a ese sinvergüenza, a ese Hinojosa, que es como decir Finojo... Pertenece a la banda de pajarracos que apenas establecida la República se cuelan en ella para llenar sus buches con los desperdicios del presupuesto. Tu enemigo es de los primeros que han llegado, quitándose las plumas alfonsinas para ponerse la cresta roja que gastan los demagogos" (IV, 582). En esa atmósfera no es de extrafiar que la República se devorara tan rápidamente a sí misma.

La proclamación de la República había causado euforia entre las clases populares, porque pensaban que la carda de la monarquía significaba el fin de sus padecimientos. La veran como la redención definitiva, puesto que Pi y Margall venía prometiendo una mejor economía, la enseñanza gratuita, 
la emancipación de la mujer, la enajenación de las tierras para los campesinos y mucho más que les alagaba. La realidad, sin embargo, resultó muy distinta. De hecho, Galdós calificó aquel acto del Congreso el 23 de abril de 1873 de "....un paso de comedia lírico-parlamentaria" (IV, 603), y las celebraciones en las calles de carnaval: "Los actos de la calle fueron un continuo ir y venir de nutridas comparsas, que disparaban víctores y exclamaciones de sorpresa o de júbilo. Otras comparsas mejor vestidas salfan corriendo por el foro, y se tiraban al foso o se subían al telar" (IV, 603). Los principales caracteres de esa comedia bufa eran unos hombres de poca entereza y de espíritu débil, unos arlequines. Entre ellos contaba el novelista al primer presidente de la República, Estanislao Figueras. Para mostrar la flaqueza e indecisión del progresista convertido en republicano, refirió como su sefrora, cuya beatería y misticismo le impelían a disuadir a su hereje marido de que castigara a personas y corporaciones religiosas, le ponía en los bolsillos de la levita carinosas notas saturadas de piedad. Esto conmovía mucho al Presidente, que de otra forma no escuchaba los sermones de su esposa. Resulta que en cierto Consejo de Ministros Figueras apoyó enérgicamente la exclaustración inmediata de unas monjas. Luego en otro Consejo cambió de opinión, porque decía que le pesaba el daño que se iba a causar a las pobrecitas hermanas. Al escuchar razones tan sensibleras e impropias de un presidente de la República, Pi y Margall conocedor de lo que pasaba le reprochó: "Vamos, Estanislao, ya has recibido carta de la familia. ¿/Me dejas registrarte el bolsillo de la levita?"' (IV,631). Con tan extravagantes e irresolutos líderes no es extrafo que anduviese el país todo revuelto. Ante tan descorazonada situación, Galdós no pudo más que exclamar: "De este pesquisar minucioso y constante saqué la impresión de hallarme en un pueblo de locos" (IV, 605).

Ya se ha menciondo la opinión de John Kronik de que el uso del grotesco fantástico se halla considerablemente reducido en Galdós: "Much diminished is the fantastic grotesque, with its emphasis on the metaphysical, the oneiric, the superhuman, the abysmal, and the ominous."15 $\mathrm{Si}$ bien esto es válido dentro de las novelas consideradas por este crítico, hay que tener presente que no estudió toda la novelística galdosiana. Para empezar, exluyó los Episodios sobre cuya serie final ya había escrito M. Enguídanos: "No cabe duda de que son los fantasmas los que parecen dominar la escena de la serie final." 16 Con tal sobreabundancia de fantasmas literarios el novelista se ha propuesto expresar también la realidad histórica española, representando de manera grotesca la inhumanidad de sus gobernantes y el sufrimiento de sus víctimas. Utilizó lo sobrehumano, lo monstruoso y lo onfrio con gran efectividad en su sátira contra los líderes de la República. Se trata de una condena política paralela a la observada hasta aquí en sus ata- 
ques directos a las distintas sítuaciones e individuos, pero dirigida además por implicación a otros partidos, al ambiente espanol inmediato anterior y, lo que es más significativo todavía, a las circunstancias político-sociales posteriores hasta el momento mismo de 1911 en que escribió La Primera República. De otro modo le hubiera sido imposible ridiculizar el gobierno de Alfonso XIII.

Condenando las deplorables condiciones políticas y sociales de ese tiempo con el recurso grotesco, Galdós llegó a la realidad a través de la distorsión mediante símbolos fantásticos. Un caso clave se tiene el día que Tito fue a visitar a uno de sus amoríos, Floriana, que se encontraba de marcha y lo invitó a que la acompanase. Desde este punto da comienzo el suefio literario galdosiano. De repente se encontraron en medio de Madrid en una especie de catacumba con una inmensa bóveda pétrea y un abismo insondable abajo. Floriana estaba ahora transformada en una diosa y, como a Goya en los Caprichos "El suefio de la razón produce monstruos," también a Galdós se los producía el mundo de sus sueños. Aterrado comenzó a imaginarse que de las oquedades: “...salían cuerpos movibles, animales felinos del mismo color que aquel terrazgo amarillento. Se me erizó el cabello al oír espantosos rugidos... No podía dudarlo: de los pefascales areniscos salían tigres, panteras y otras alimanas rampantes, cuyo aspecto y bramidos pondrían pavor en los pechos más animosos..." (IV, 636). He ahí su amarga sátira grotesca contra la inmoralidad, la rapacería, la irresponsabilidad y la ambición de aquellos políticos y generales de su tiempo, rasgos encarnados en los atributos negativos de las diferentes fieras de la cita. En todos sobresale la máscara de la hipocresía con que engaffaban al país. En esa descripción de sugerencias repulsivas están representados seres en su opinión tan despreciables como Sagasta, el parásito Hinojosa, Nicolás Mạ Rivero, Pavía, Serrano, Cánovas del Castillo, o sus predecessores como Narváez, O’Donnell, Posada Herrera y demás sanguijuelas de la patria: carlistas, alfonsinos y otros de similar calafra. La visión galdosiana prosigue, dirigiéndose un poco más adelante a sus lectores en estos términos: "Imaginad, amigos del alma, cuál sería mi espanto al ver venir hacia mí un toro..., iay madre mía!..., un toro tan grande que a mi parecer era mayor que los más corpulentos elefantes, colorado retinto, por su porte y lámina de genuina casta española, con una cornamenta que a Dios llamaba de tú..." (IV, 636). A este toro le seguían otros, siendo todos del mismo color y aspecto. El significado de su simbolismo resulta suficientemente explícito para reconocer su sátira política de aquella Espana. Además esto se encuentra expresado de una forma más explícita todavía unas páginas después cuando una de las diosas, o ninfas, se dirige a Mariclío, diciendo con viveza: "Lo que debe saber Tito es que muchos de los toros que ha visto son hombres" (IV, 642). 
Toda esa experiencia se le imaginaba un terrible sueffo del que deseaba despertar para olvidarse de la horrible pesadilla: "Y heme aquí sonando con lo que había dejado en el otro mundo. Así lo llamo por no saber se el otro era aquel en que me encontraba, o si me habían traído efectivamente al que allá llamábamos el otro. íSueno de suefios!" (IV, 637). Pero descubrió con gran dolor que no eran sólo fantasmas de su estado onírico, sino la triste realidad cotidiana: "Pues, señor, me vi en el congreso (tribuna de la Prensa), oyendo un discursazo de Salmerón, magnífico, elocuente. Cuando terminó todos decían: 'Ya hay Gobierno en la República espafiola.' Aquello se me representaba como un teatro de nifos, con figurillas diminutas que se movía con alambres... Luego soñé que pedía la palabra Ríos Rosas. Prodújose un tumulto, porque alguien pretendió que no se dejara hablar al orador monárquico..." (IV, 637). Entonces, de modo similar a Segismundo en $\mathrm{La}$ vida es sueño de Calderón, Galdós se prégunta: “...łla realidad era lo de allá o lo de acá? ?Eran este y el otro mundo igualmente falaces o igualmente verdaderos?" (IV, 638). Pero no le dio tiempo a discernirlo, porque la caravana se puso en marcha y continuó la visión. Ahora ya se hallaban en las regiones levantinas frente a los problemas cantonales que, en realidad, eran consecuencias de los anteriores. Se encontraron en el cabo de Palos camino de Cartagena, donde se despidió de Floriana hasta el día siguiente. Cartagena y Murcia resistían los ataques del gobierno de Madrid, sublevadas desde el 14 de julio. La Rosa mantiene que el alzamiento de Cartagena fue de tipo político, no era un movimiento separatista, sino una aplicación de la teoría pactista de Pi y Margall. ${ }^{17}$ El novelista, sin embargo, parece considerarlo un movimiento separatista para formar una pequeña nación que de nueva sólo tenía el nombre, pues las instutuciones, proceso y filosofía eran las mismas de la vieja Espafia: “- iAh sefiora! Aquí tenemos una pequefra nación con todos los requilorios de una nación vieja y grande... Tenemos Comité de Salud Pública, Generalísimo de los Ejércitos de Mar y Tierra, Tesorería... sin un cuarto; y para que nada falte, piensan acunar moneda..." (IV, 647). El escritor condenaba del cantonalismo esa continuación de los mismos males que afectaban al resto del país, lo cual sólo venía a agravar más la situación.

\section{CONDENA DEL BORBONISMO Y DE LA ENSEÑANZA}

Desde el momento que Salmerón confió el mando de las tropas al enemigo de los federales, general Pavía, y al alfonsino general Martínez Campos, la República quedó a la voluntad del ejército que la hundiría con increible rapidez. En efecto, políticamente el primero de estos generales ter- 
minó con la República y el segundo reinstauró la monarquía borbónica el 29 de diciembre de 1874 . Fue éste un ano de excesiva turbulencia, a la cual se refirió Galdós con amargo disgusto al decir que el país entero pedía orden y paz. Alfonso XII llegó a Madrid el 14 de enero de 1875, lo cual supońa para el novelista un obstáculo mayor todavía a sus ansias de libertad, mejora y progreso que los considerados hasta el presente: “...porque ya entramos en la era de la hipocresía, del mírame y no me toques, y del buen callar, que llamamos Sancho" (IV, 787). Expresó su desacuerdo con la política retrógrada del absolutismo borbónico en unas páginas más adelante de Cánovas, retratando al gobierno del joven Alfonso como un monstruo que iba a devorar a Espafra: "Lo que hemos visto es el familión político triunfante, en el cual todo es nuevo, desde el Rey, cabeza del Estado, hasta las extremidades o tentáculos en que figuran los últimos ministriles; es un hermoso y lucido animal, que devora cuanto puede y da de comer a lo que llamamos pueblo, nación o materia gobernable" (IV,798). En su concepto ese pueblo sostenido por la nueva situación política no significaba la muchedumbre jornalera del campo, sino los parásitos políticos de todas las clases sociales empleados de las diversas oficinas y dependencias del gobierno al servicio siempre de quien estuviera en el poder:

Me refiero a la clase que constituye el contingente más numeroso y desdichado de la grey espaffola; me refiero a los míseros de levita y chistera, legión incontable que se extiende desde los bajos confines del pueblo hasta los altos linderos de la aristocracia; caterva sin fin, inquieta, menesterosa, que vive del meneo de plumas en oficinas y covachuelas, o de modestas granjerías que apenas dan para cocido. Esta es la plaga, ésta es la carcoma del país, necesitada y pedigüena, a la cual, ibh ilustre companera mia! tenemos el honor de pertenecer. (IV, 799)

El gran artífice de la restauración, que puso en marcha toda esa plaga política de Alfonso XII y también de su sucesor, fue Cánovas del Castillo. Este recibió una carta de Isabel II, desterrada en París, con plenos poderes para conseguir en España la coronación de su hijo: "por cuantos medios y recursos puedas." 18 Después de entrevistarse con dona Isabel en París, Cánovas desarrolló una intensa actividad, ut nlizando el sistema establecido por Posada Herrera en 1858, pero con una coacción moral al elector más fuerte, con mayor degradación y con mayor corrupción política en todos los sentidos. Por eso Galdós se refirió lleno de indignación al sistema político borbónico en estos términos: "El borbonismo no tiene dos fases, como creen los 
historiadores superficiales, sino una sola. Aquí y allá, en la guerra y en la paz, es siempre el mismo, un poder arbitrario que acopla el Trono y el Altar para orpimir a este pueblo infeliz y mantenerlo en la pobreza y en la ignorancia" (IV, 824). Tal afirmación, junto con otras de tono similar, parece inferir que para el novelista no sólo era ésa la realidad de la Restauración y del pasado durante aquel siglo, sino que seguiría aconteciendo lo mismo mientras la corona espafiola estuviera en manos de Borbones absolutistas. Su pesimismo está bien justificado por la historia, pues la Constitución de 1876 estuvo vigente hasta su suspensión por el dictador Primo de Rivera en 1923, y volvió a ser puesta en vigor a su caída en 1930.

El despotismo borbónico le resultaba inmensamente más pernicioso, corrupto y brutal en el carlismo, pues además de arbitrario lo percebŕa como fanático. Si bien es cierto que al principio había contado con algunos líderes de la honradez y valor de Tomás Zumalacárregui, de Bruno Villareal y de Miguel Gómez, a partir del reinado de Amadeo I sus filas estaban llenas de clérigos guerrilleros y de cobardes jefes de partidas sin prestigio ninguno. Utilizando el método del Padre Isla en su Fray Gerundio, ridiculizó el fanatismo carlista tanto como la República en un irónico discurso grotesco pronunciado por el insigne Tito en Bilbao:

- iSí, la República!... Pero no es aquella bacante semidesnuda y escandalosa, hija de Satán, que trastorna con su bello nombre y su infernal doctrina a los pueblos y ciudades de Castilla; no es la bestia roja, sanguinaria, ebria de vino y de mentirosas filosofías; no es ésa, no. Esa República será barrida como los despojos de Carnaval que ensucian las calles el Miércoles de Ceniza; ...La República que yo preconizo y anuncio es otra: es la que lleva en sus sienes, por corona, la luz del Espiritu Santo, la que en los bordes de su clámide lleva bordadas las inscripciones: $F e$, Esperanza y Caridad;... (IV, 539)

Sin mencionarlo, aquí se condena el fanatismo clerical carlista que no sólo aceptaba el Sylabus de Pío IX, como el resto de Espafia, recuérdense los carteles colgados en Madrid diciendo: "iViva el Papa Rey!" y "iViva el Sylabus!," sino que incluso contaba en sus filas con los sacerdotes más incultos y de costumbres más licenciosas. Las acciones de muchos de éstos contribuyeron tanto, o más, al anticlericalismo popular como la Constitución de 1869 y el anticlericalismo de los progresistas y republicanos. Ese anticlericalismo popular y la condena de la Iglesia en decadencia es rotunda en Cánovas al relatar como silvaron en la Rambla de Barcelona a los capuchi- 
nos que venfan desterrados, a quienes caracterizó como: “...una banda de capuchinos proceros, bien cebados y con unas barbas hasta la cintura" (IV, 869). A los frailes que desembarcaron en Almería los pintó en su versión de deformidad externa, reflejo de la decadencia de su estado: “...desembarcaron unos frailucos mal trajeados, desnudos de pie y pierna, si que también muertos de hambre" (IV, 870). Su visión de lo que esa inundación de religiosos significaba para España quedó resumida por una de las Efémeras al despedirse de Tito: “- Vamos a llevar por todo el mundo las nuevas de esta plaga de insectos voraces que devastará tu tierra" (IV, 870). La Restauración encarnaba para Galdós el reinado de las santurronerías bobaliconas y la conversión de Espana en un gran monasterio, pero imaginaba al carlismo mucho peor todavía. Para empezar, Don Carlos, el pretendiente, era un ser sin inteligencia ninguna, a quien dona Lupe en Fortunata y Jacinta retrató así: "...aquel zagalón de don Carlos, un perdido, un zafiote, un déspota en toda la extensión de la palabra" (II, 641). Encima, confiaba en aquellos curas interesados sólo en su ganancia material, los cuales le llenaban la cabeza de calumnias contra sus fieles jefes militares y lo traicionaban. Buen ejemplo de lo que era ese clero que rodeaba al pretendiente se tiene en $\mathrm{Ni}$ colás Rubín. Su propia tía, dona Lupe, decía que tenía tanta barba que incluso al terminar de afeitarse sus mandibulas parecían una pizarra. El vello le crecía en las manos tan espeso como la hierba en un fértil prado y de los oídos y cavidades nasales le salían espesos mechones, en una palabra, un gorila humano. Su voraz apetito predominaba sobre sus devotas actividades pastorales:

Para principio del clérigo pones la merluza mala que trajiste esta mafiana, isabes?, y que está apestando... Le echas bastante sal, y después la cargas de harina todo lo que puedes y la fríes. Ponle todas las tajadas, y se las embaulará sin enterarse de si está buena o mala. Es como los tiborones, que tragan todo lo que le echan. Para postre, las nueces y el arrope, isabes? Le pones en la mesa la orza, y que se harte; a ver si lo acaba. (II, 793)

No cabe duda que esas deformidades externas encarnan el interior de la persona, quien, a pesar de su estupidez, llegó a ser canónigo de Orihuela.

Además de los males considerados, se necesita examinar la precaria situación de la ensenanza, consecuencia de la desastrosa condición política del país, lo mismo que las otras calamidades. A Galdós, para quien la enseñanza era la clave del triunfo social, le dolía el atraso intelectual de Espafia. Históricamente los estudios universitarios espaffoles del siglo pasado eran poco 
sólidos por la carencia de profesorado capaz, de bibliotecas y de laboratorios, lo cual tuvo trágicos efectos para el país. Hasta la caída de Isabel II la universidad estuvo también totalmente sometida a los deseos del clero, produciendo dafios severos adicionales a los estudios de la mayor parte de las ramas del saber, principalmente a los de las ciencias. En Fortunata y Jacinta se encuentra un ejemplo muy iluminador de su perspectiva sobre el triste estado de la formación universitaria espafiola de aquel tiempo, que refleja de manera grotesca la realidad. Los estudiantes en las clases no prestaban atención al catedrático, sino que pasaban el tiempo charlando, leyendo novelas, dibujando caricaturas y haciendo otras muchas tonterías: "Juanito Santa Cruz y Miquis llevaron un día una sartén (no sé si a la clase de Novaro a la de Uribe, que explicaba Metafísica) y frieron un par de huevos" (II, 447). La ensefranza elemental sẻ hallaba en peor estado, quizá, que la superior. Por una parte, escaseaban las escuelas, sobre todo en lugares rurales, y los gobiernos se oponían a abrir más. La Rosa cuenta que en cierta ocasión le pidieron a Bravo Murillo la creación de una escuela para seiscientos adultos, a lo cual respondió el ministro: "Aquí no necesitamos hombres que piensen, sino bueyes que trabajen." 19 Por otra, en las pocas escuelas que había se usaban métodos de ensenanza brutales, como corregir las equivocaciones a correazos. Tampoco las materias que se ensefraban eran las más fundamentales ni la manera era la más pedagógica. Enseñaban cantando la doctrina cristiana y las listas de los reyes, de las capitales de provincia y de los ríos. Además los limitadísimos maestros competentes en muchos casos tenían que dejar la ensenanza para dedicarse a algo que les permitiera vivir económicamente, como parece indicar Galdós con el ejemplo del grotesco don José Ido del Sagrario en Amadeo I: "Quedo, pues, en situación de esqueleto vestido de flácidas carnes; no resistía ningún trabajo fuerte, físico ni mental: ocupábase tan sólo en repartir entregas de una casa editorial, reduciéndose a un corto callejero,..." (IV, 516). Aunque su nueva ocupación le proporcionó una pequeña mejora económica, no le sacó de la miseria, consecuecia fácilmente deducida del no menos grotesco retrato que el novelista había hecho de este personaje en Fortunata y Jacinta después de pasar de maestro de escuela a repartir entregas de la editorial:

Al poco rato entró en el despacho un hombre muy flaco, de cara enfermiza y toda llena de lóbulos y carúnculas, los pelos bermejos y muy tiesos, como crines de escobillón; la ropa prehistórica y muy raf́da, corbata roja y deshilachada, las botas muertas de risa. En una mano tráa el sombrero, que era um claque del ano en que esta prenda se inventó, el primogênito de los claques sin género de duda, y en la 
otra un lío de carteras-prospectos para hacer suscripciones a libros de lujo, las cuales estaban tan sobadas, que la mugre no permitía ver los dorados de la pasta. Impresionó penosamente a la compasiva Jacinta aquella estampa de miseria en traje de persona decente, y más lástima tuvo cuando le vio saludar con urbanidad y sin encogimiento, como hombre muy hecho al trato social. (II, 524)

Por comparación del estado de Ido en la nueva ocupación con la anterior de maestro, se puede ver claramente la condición más que infrahumana en que debían encontrarse los profesores espanoles de aquella época. Mediante lo grotesco de la inhumanidad exterior aquí se observa la belleza interior de la persona de Ido. De esa forma, al propio tiempo que revela su excelsitud, demuestra lo grotesco de la situación política causante de tan precarias condiciones. Lo peor es que la inmensa mayor ía de los maestros eran incompetentes, una gran proporción de ellos incluso se le figuraban a Galdós unos analfabetos. Para ilustrar este hecho baste mencionar el caso de la analfabeta Casiana, la amante de Tito. En Cánovas éste se la presentó, bromeando, a unos amigos con poder como una prima recién llegada de Cuba con la aspiración de ocupar una plaza en la Escuela Normal de Maestras. Uno de ellos les ofreció intervenir ante su amigo el director de Instrucción Pública para que le diese un puesto preeminente. Efectivamente, al poco tiempo recibieron la credencial nombrando a Casiana inspectora de escuelas con 10.000 reales de sueldo por sus grandes conocimientos pedagógicos. Además, en nota a parte, le decía que si Casiana daba lecciones particulares a domicilio: “...quedaría relevada de todas las obligaciones de la Inspección, salvo la de cobrar su sueldo a primeros de cada mes..." (IV, 806). El relato termina con el comentario de que esto era lo corriente en sus tiempos: "Todo era ficciones, favoritismos y un saqueo desvergonzado de Presupuesto...” (IV, 807).

Mucho más se podía decir sobre éstos y otros puntos de los escritos galdosianos, pero baste con unos comentarios de conclusión. Las novelas aquí estudiadas permiten afirmar que sus obras son los documentos más vivos de aquellos trágicos acontecimientos de Espafia, interpretados de acuerdo con la visión personal del autor. Su uso del recurso grotesco para la sátira política resulta muy efectivo y también acertado desde el punto de vista estético. Por este medio de expresividad histórica, Galdós parece afirmar tajantemente que en aquel presente España era un país sin constituirse todavía en el aspecto aquí considerado y sus esperanzas, a pesar de la sombría situación a la vista, yacían en el futuro. La mejora, sin embargo, no tendría lugar hasta que desaparecieran de la escena política los déspotas y 
sus serviles ejectores, como muy bien se desprende de las siguientes líneas de Cánovas:

En el propio estado de pérfida legalidad seguirra viviendo nuestra nación año tras año, hasta que otros hombres y otras ideas nos trajeran la política de la verdad y la justicia, gobernando, no para una clase escogida de caballeros y seforas, sino para la familia total que goza y trabaja, triunfa y padece, ríe y llora en este pedazo de tierra feraz y desolado, caliente y frío, alegre y tristísimo que llamamos Espaกล. (IV, 825-26).

NOTAS

${ }^{1}$ Véase Peter Bly, Galdos's Novel of the Historical Imagination (Liverpool: Francis Cairns, 1983), pág. 86

${ }^{2}$ Véase Hans Hinterhäuser, Los "Episodios Nacionales" de Benito Pérez Galdos (Madrid: Gredos, 1963), pág. 117.

${ }^{3}$ Véase Miguel Enguídanos, "Mariclío, musa galdosiana," Papeles de son Armadans, No. 63 (1961), 249. También Hinterhäuser, pág. 133. Además Peter Bly, "For Self or Country? Conflicting Lessons in the First Series of the Episodios nacionales?," Kentucky Romance Quarterly, 21 (1984), 117.

${ }^{4}$ Benito Pérez Galdós, Obras completas, IV, Introducciones de F. C. Sainz de Robles, $1^{\text {a }}$ ed. (Madrid: Aguilar, 1971), pág. 679. Todas las referencias a los Episodios aparecerán con el número de este tomo y página, para Fortunata y Jacinta, II, $1^{\mathrm{a}}$. ed., (1970).

${ }^{5}$ Véase Hinterhäuser, págs. 148-49.

${ }^{6} \mathrm{El}$ estudio de Bäuml, "The Mundane Demon: The Bourgeois Grotesque in Galdós' Tor quemada en la hoguera," se publić en Symposium, 24 (1970), 158-65; John W. Kronik publicó su "Gal̃ós and the Grotesque" en Anales Galdosianos, Anejo, (1978), 39-54, donde mantiene: "Thie glimpse into the grotesque in Galdós is necessarily incomplete. I have not even mentioned Dona Perfecta or La de Bringas. I have bypassed the Beauty/Beast inversions in La loca de la casa and in El caballero encantado... The Episodios nacionales and the plays have not been adduced as evidence." (págs. 51-52).

${ }^{7}$ Mariano Baquero Goyanes, "Las caricaturas literarias de Galdós" en Perspectivismo y contraste (Madrid: Gredos, 1963), pág. 47. 
$8_{\text {Bäuml, pág. } 164 .}$

${ }^{9}$ Kronik, pág. 41.

10Véase Tristán La Rosa, España Contemporánea: Siglo XIX (Barcelona: Ediciones Destino, 1972), págs. 239-41.

${ }^{11}$ Frase citada por La Rosa, pág. 238.

${ }^{12}$ Eguídanos, pág. 241.

${ }^{13}$ Véase el recuento histórico que hace La Rosa, págs. 287-288.

${ }^{14}$ Véase Kronik, pág. 42.

15 Kronik, pág. 41.

16Enguídanos, pág. 244.

${ }^{17}$ Véase lo que dice La Rosa, quien incluso cita el pacto de Tortosa del 18 de mayo de 1870 , págs. 314-15.

${ }^{18}$ Citada por La Rosa, pág. 330.

${ }^{19}$ Tomada de La Rosa, pág. 273.

"Department of Langages

University of utah

Salt Lake City, UT 84112

USA. 